\title{
Influence of initiators on the sintering discolouration of PTFE
}

\author{
W.V. Venner, G.J. Puts, P.L. Crouse \\ Department of Chemical Engineering, Faculty of Engineering, Built Environment and \\ IT, University of Pretoria
}

\section{Highlights}

- PTFE was synthesised with persulfates, $\mathrm{H}_{2} \mathrm{O}_{2}, \mathrm{KMnO}_{4}$ and di(tert-butyl) peroxide as initiators.

- Discolouration was not a strong function of molecular weight. Persulfates and $\mathrm{KMnO}_{4}$ showed the most discoloration.

- Raman spectroscopy showed the presence of graphite and amorphous carbon in the post sintered mass of highly discoloured PTFE.

- Glassy carbonaceous material was found after pyrolysis of $\mathrm{KMnO}_{4}$ initiated PTFE.

- Discolouration is due to carbon deposition into the polymer matrix generated by the decomposition of unstable end-groups.

\begin{abstract}
PTFE homopolymer synthesised using ammonium persulfate initiator discolours at sintering temperatures of approximately $380{ }^{\circ} \mathrm{C}$. No report on this phenomenon is available in the open literature. To shed light on the problem, PTFE samples were synthesised using various initiators and different $\mathrm{pH}$ buffers. The initiators used included ammonium persulfate, sodium persulfate, potassium permanganate, di-tertiary butyl peroxide and hydrogen peroxide. Borax and potassium carbonate were used as the buffering agents. The samples were pressed into discs and sintered at $380^{\circ} \mathrm{C}$. The samples were analysed using FTIR and Raman spectroscopy to determine the influence of decomposition of the end-groups during sintering. Each initiator resulted in unique end-groups, with a suggestion of multiple termination reactions in several of the samples. The discolouration of the samples occurs because of amorphous carbon deposition into the polymer matrix after elimination from the end-groups during sintering. The level of discolouration is dependent on the type and concentration of initiator used.
\end{abstract}


Graphical abstract

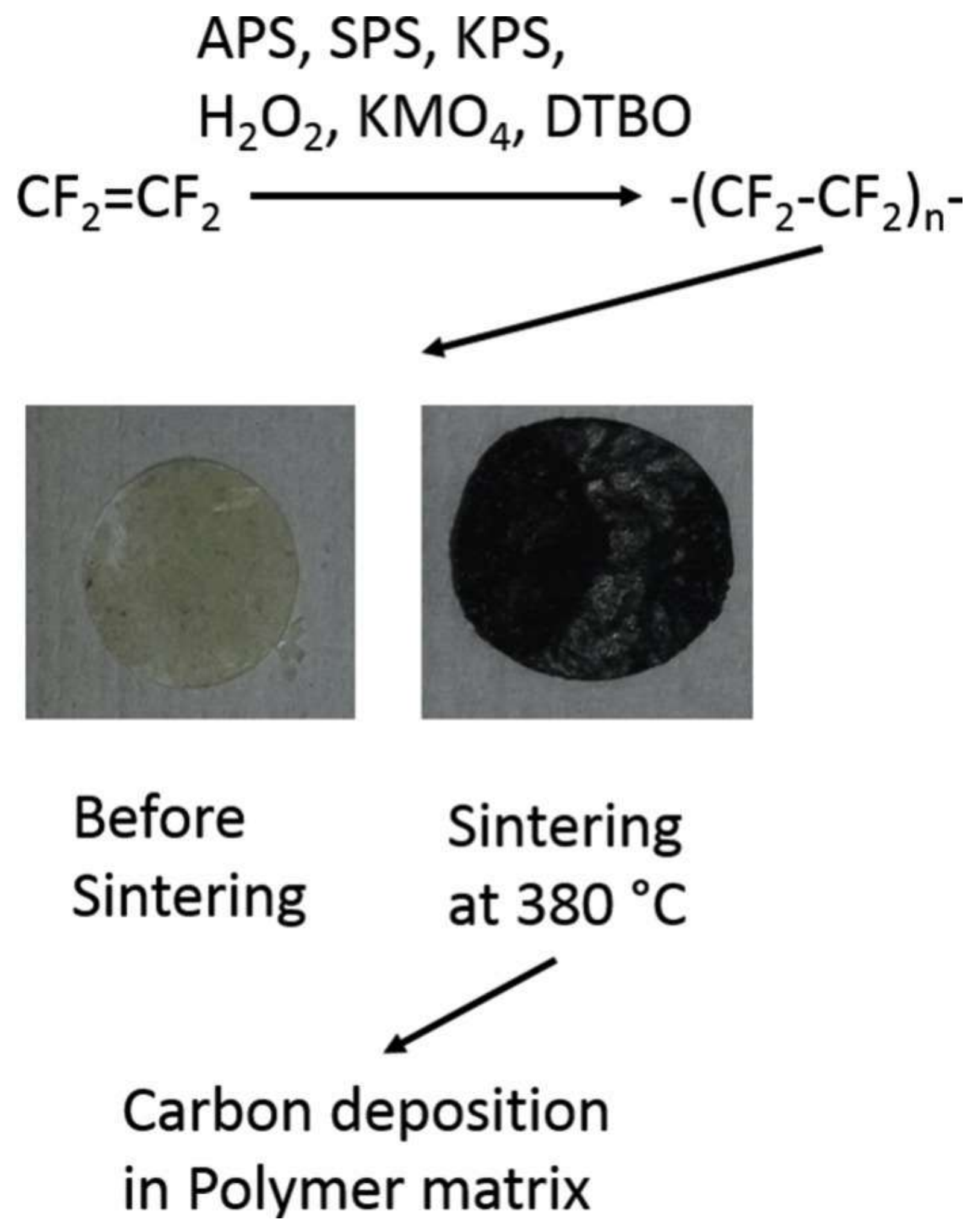

Keywords

PTFE discoloration; TFE polymerisation; PTFE radical initiators; Polymer end-groups 


\section{Introduction}

Fluorinated polymers are niche macromolecules that play an essential role in modern life [1], and due to the properties of fluorine (including, among others, large electronegativity, low polarizability, and a small van der Waals radius of $1.32 \AA$ ) and the strong $\mathrm{C}-\mathrm{F}$ bonds (485 $\mathrm{kJ} \cdot \mathrm{mol}^{-1}$ ), they exhibit unique and remarkable properties [2]. Their applications span engineering thermoplastics and elastomers for the chemical-process, automotive and aeronautics industries, weather-proof coatings, biomedical materials, separators, electrolytes, binders for Li-batteries, exchange membranes in fuel cells, and many more [1, 3-12]. Poly(tetrafluoroethylene) (PTFE) discovered in 1938 by Roy Plunkett [13], was the first fluoropolymer to be commercialised and has played a major role in many high-tech applications throughout its 80 year history. Numerous other fluoropolymers have been commercialised between 1938 and the present. However, PTFE remains the predominant commercial fluoropolymer. This material and its marginally modified derivatives comprised approximately $60 \%$ of the total international fluoropolymer market in 2015 $[14,15]$.

PTFE is usually synthesised by polymerising tetrafluoroethylene (TFE) via an aqueous free-radical process. Initiators employed include bisulfites, metal fluorides, persulfate compounds, strong oxidisers, redox compounds, as well as many water-soluble organic compounds [16-22]. The polymerisation process is highly exothermic $\left(\Delta \mathrm{H}_{\mathrm{R}}=-196 \mathrm{~kJ} / \mathrm{mol}\right.$ TFE$)$ [23] and the monomer may easily undergo deflagration [24]. These factors make the polymerisation of TFE a dangerous undertaking. As a result, the homopolymerisation of TFE has seen little treatment in the Englishlanguage scientific literature as few academic institutions are willing to accept the risks involved in the handling and polymerisation of TFE.

There is a definite gap in the available literature regarding the effects of the polymerisation conditions on the properties of the product PTFE. In particular, little mention has been made regarding the effects different initiators have on the polymer. It is generally believed that the type of initiator does not play a significant role in the mechanical properties of high-polymers such as PTFE, because the end-groups are present in such minute concentration. However, it has been found that end-groups have a significant effect on the thermal stability and colour of fluoropolymers $[25,26]$. For example, PTFE initiated with persulfate initiators are known to undergo discoloration upon sintering (thermal treatment at $380{ }^{\circ} \mathrm{C}$ ), with the degree of discoloration depending strongly on the molecular weight of the polymer.

The end-groups in fluoropolymers were discussed by Pianca et al. [26]. Some of the identified endgroups found in PTFE initiated by persulfates include $(\mathrm{C}=\mathrm{O}) \mathrm{OH},(\mathrm{C}=\mathrm{O}) \mathrm{NH}_{2}, \mathrm{CF}_{2} \mathrm{H},(\mathrm{C}=\mathrm{O}) \mathrm{F}$, 
$\mathrm{S}(=\mathrm{O})_{2} \mathrm{OH}$ and $(\mathrm{C}=\mathrm{O}) \mathrm{O}^{-} \mathrm{X}^{+}$, where $\mathrm{X}$ is a metal (such as $\left.\mathrm{Na}, \mathrm{K}, \mathrm{Li}\right)$ or an ammonium group. Thermal treatment of these end-groups generally result in the formation of $\mathrm{C} \equiv \mathrm{N}$ or $\mathrm{CF}=\mathrm{CF}_{2}$ endgroups.

The open literature fails to explain adequately why the polymer undergoes discolouration as none of the mentioned end-groups are optically active and they do not absorb or fluoresce in the visible light spectrum. Hence, the actual cause of the discolouration is unknown, or more probably least, unreported.

This article presents the results of our investigation into the effect of various initiators on the discoloration observed in PTFE and focuses particularly on determining the cause of the discoloration.

\section{Results and discussion}

Batches of PTFE were synthesised using some common conventional free-radical initiators. The results for ammonium persulfate (APS) initiated polymerisation are presented in Table 1 . The results for sodium persulfate (SPS), $\mathrm{KMnO}_{4}, \mathrm{H}_{2} \mathrm{O}_{2}$, di-tertiary-butyl peroxide (DTBP), 4,4'azobis(4-cyanopentanoic acid) (ACPA), 2,2'-azobis(2-methylpropionamidine) dihydrochloride (AAPH), benzoyl peroxide (BPO), and lauroyl peroxide (LPO) are presented in Table 2.

For the APS initiated PTFE, sodium tetraborate was used as a buffering agent (except for experiment 2). One synthesis was also carried out using APS with $\mathrm{K}_{2} \mathrm{CO}_{3}$ buffering agent. This was done to investigate whether a different buffering agent, or lack thereof, had any effect on the end-groups of the polymer. All other initiators were employed sans buffering agent.

APS initiated samples were isolated as granular powders with an off-white to light-yellow colour, depending on the initiator concentrations. In general, the higher the initial initiator concentration, the more yellow the product powder. Once pressed into thin discs, they generally became translucent. Reaction temperature did not seem to have an influence on the colour of the samples.

Samples initiated with the other metal-containing inorganic initiators as well as the DTBP were also isolated as granular powders. The $\mathrm{H}_{2} \mathrm{O}_{2}$ initiated PTFE was isolated as thin translucent sheets. BPO, LPO, ACPA and AAPH did not initiate any polymerisation of TFE. For BPO and LPO this is due to their low solubility in water. No literature could be found that explains why water-soluble initiators such as ACPA and AAPH do not initiate TFE homopolymerisation. 
Table 1: Results of the TFE polymerisations using APS as initiator.

\begin{tabular}{|c|c|c|c|c|c|c|}
\hline $\begin{array}{l}\text { Exp. } \\
\text { number }\end{array}$ & Temp. $\left({ }^{\circ} \mathrm{C}\right)$ & Mass TFE (g) & $\begin{array}{l}\text { Initiator } \\
(\%)\end{array}$ & $\begin{array}{l}\text { Vol. water } \\
(\mathrm{mL})\end{array}$ & $\begin{array}{l}\text { Mass of buffer } \\
\text { (g) }\end{array}$ & $\begin{array}{l}\text { Degree of discolouration } \\
\text { after sintering }\end{array}$ \\
\hline 1 & 65 & 5 & 5,5 & 100 & 0.48 & 5 \\
\hline 2 & 65 & 5 & 5,5 & 100 & - & 2 \\
\hline 3 & 50 & 5 & 5.5 & 100 & 0.48 & 5 \\
\hline 4 & 55 & 5 & 2,3 & 100 & 0.48 & 7 \\
\hline 5 & 55 & 5 & 5,5 & 100 & 0.48 & 8 \\
\hline 6 & 55 & 5 & 8,7 & 100 & 0.48 & 8 \\
\hline 7 & 65 & 5 & 1,0 & 100 & 0.48 & 8 \\
\hline 8 & 65 & 5 & 2,0 & 100 & 0.48 & 7 \\
\hline 9 & 65 & 5 & 5,5 & 100 & 0.48 & 6 \\
\hline 10 & 65 & 5 & 8,7 & 100 & 0.48 & 7 \\
\hline 11 & 65 & 5 & 10 & 100 & 0.48 & 6 \\
\hline 12 & 65 & 5 & 20 & 100 & 0.48 & 2 \\
\hline 13 & 75 & 5 & 2,0 & 100 & 0.48 & 7 \\
\hline 14 & 75 & 5 & 5,5 & 100 & 0.48 & 4 \\
\hline 15 & 75 & 5 & 8,7 & 100 & 0.48 & 5 \\
\hline 16 & 75 & 5 & 10 & 100 & 0.48 & 3 \\
\hline 17 & 80 & 5 & 5,5 & 100 & 0.48 & 3 \\
\hline 18 & 80 & 5 & 10 & 100 & 0.48 & 3 \\
\hline 19 & 50 & 5 & 5,5 & 100 & 0.18 & 6 \\
\hline
\end{tabular}


Table 2: $\quad$ Results of the TFE polymerisations using various other initiators, sans buffering agent.

\begin{tabular}{llllllll}
\hline $\begin{array}{l}\text { Exp. } \\
\text { number }\end{array}$ & Initiator & $\begin{array}{l}\text { Temp. } \\
\left({ }^{\circ} \mathrm{C}\right)\end{array}$ & $\begin{array}{l}\text { Mass } \\
\text { TFE } \\
(\mathrm{g})\end{array}$ & $\begin{array}{l}\text { Initiator } \\
\%\end{array}$ & $\begin{array}{l}\text { Vol. water } \\
(\mathrm{mL})\end{array}$ & $\begin{array}{l}\text { Yield } \\
(\%)\end{array}$ & $\begin{array}{l}\text { Degree of } \\
\text { discolouration after } \\
\text { sintering }\end{array}$ \\
\hline 20 & SPS & 65 & 5 & 5.5 & 100 & 88.1 & 1 \\
21 & SPS & 65 & 5 & 30 & 100 & 66.8 & 2 \\
22 & $\mathrm{KMnO}_{4}$ & 35 & 5 & 1 & 100 & 38.6 & 0 \\
23 & $\mathrm{KMnO}_{4}$ & 35 & 5 & 10 & 100 & 51.6 & 0 \\
24 & $\mathrm{KMnO}_{4}$ & 35 & 5 & 30 & 100 & 27.7 & 10 \\
25 & DTBP & 135 & 5 & 1 & 100 & 57.0 & 1 \\
26 & DTBP & 135 & 5 & 10 & 100 & 57.1 & 1 \\
27 & DTBP & 135 & 5 & 30 & 100 & 27.7 & 1 \\
28 & H2O & 80 & 5 & 10 & 100 & 73.8 & 0 \\
29 & ACPA & 80 & 5 & 10 & 100 & 0 & $\mathrm{n} / \mathrm{a}$ \\
30 & AAPH & 80 & 5 & 10 & 100 & 0 & $\mathrm{n} / \mathrm{a}$ \\
31 & BPO & 85 & 5 & 10 & 100 & 0 & $\mathrm{n} / \mathrm{a}$ \\
32 & LPO & 85 & 5 & 10 & 100 & 0 & $\mathrm{n} / \mathrm{a}$ \\
33 & ACPA & 55 & 5 & 0.5 & 100 & 0 & $\mathrm{n} / \mathrm{a}$ \\
34 & AAPH & 55 & 5 & 0.5 & 100 & 0 & $\mathrm{n} / \mathrm{a}$ \\
\hline
\end{tabular}




\subsection{Discolouration}

Discs were pressed from the PTFE powders and were then sintered for a period of $30 \mathrm{~min}$ to ensure that the maximum possible colour change took place. The degree of discolouration for the experiments was rated on an arbitrary scale of $0-10$, where 0 means no discolouration and 10 complete discolouration (i.e. bright white at 0 and black at 10). The before-and-after photographs for the pressed discs are given in the supporting information and the degree of discolouration is summarised in Table 1 and Table 2.

As expected, commercial PTFE did not exhibit any colour change. The commercial sample became translucent at the sintering temperature, but reverted to an opaque white when cooled to ambient.

APS initiated samples were generally off-white to a light-yellow colour depending on the initiator concentrations before sintering and in most cases discoloured mildly to varying shades of brown. SPS initiated samples were white before sintering and discoloured significantly less than the APS samples when sintered. Control experiments using potassium persulfate (KPS) also did not discolour as much as the ammonium persulfate initiated polymers.

$\mathrm{KMnO}_{4}$ initiated samples were pristine white in colour. The samples synthesised with lower initiator concentrations (1\% and 10\% respectively) showed no discolouration after sintering. However, the sample initiated with 30\% initiator showed the most pronounced discolouration of all the samples tested, going from pristine white to dark black when sintered. DTBP initiated samples were yellow to light brown in colour before sintering but underwent no change in colour when sintered. Lastly, PTFE synthesised by photo-initiation with $\mathrm{H}_{2} \mathrm{O}_{2}$ produced a pristine white polymer which underwent no colour change whatsoever during sintering.

The cause of discolouration in PTFE is not explicitly discussed in the literature. The literature indicates implicitly that the discolouration is due to chromophoric end-groups. Kurt Nassau [27] discussed the fundamental causes of colour and indicated that, for purely organic compounds (not ligands), colouration arises from conjugated p-orbitals, i.e., chains of alternating single and double bonds.

As stated previously, the literature regarding end-groups in fluoropolymers [26] indicates that APS, SPS and $\mathrm{H}_{2} \mathrm{O}_{2}$ initiated PTFE should exhibit end-groups which undergo thermolysis to produce $\mathrm{C} \equiv \mathrm{N}$ or $\mathrm{CF}=\mathrm{CF}_{2}$ terminal moieties. Specifically, the nitrile end-groups are produced only by APS. Compounds such as DTBP do not produce end-groups which eliminate at sintering and should 
not produce any discolouration (this is confirmed by the lack of discolouration during sintering for this initiator, as reported in Table 2).

The known end-groups of PTFE are not conjugated systems and do not act as chromophores for visible light. For example, $\mathrm{CF}_{2}=\mathrm{CF}_{2}, \mathrm{CF}_{3}-\mathrm{CF}=\mathrm{CF}_{2}, \mathrm{CF}_{3}-\mathrm{CF}_{2}-\mathrm{CF}=\mathrm{CF}_{2}$, etc., are reported as colourless gasses. So too the homologues of $\mathrm{CF}_{3}-\mathrm{C} \equiv \mathrm{N}[28]$.

Furthermore, assuming the end-groups are the source of the discolouration, there should be a strong correlation between the concentration of the end groups and the degree of discolouration. From Tobolski's law $[29,30]$, the molecular weight decreases with the square root of the initial initiator concentration. As the end-group concentration increases with decreasing molecular weight, a strong correlation should exist between the molecular weight and the degree of discolouration. The degree of discolouration is plotted as a function of $M_{n}$ in Fig. $1 . M_{n}$ was calculated based on the heat of recrystallization using Suwa's equation. The data do not suggest any correlation between the degree of discolouration and molecular weight.

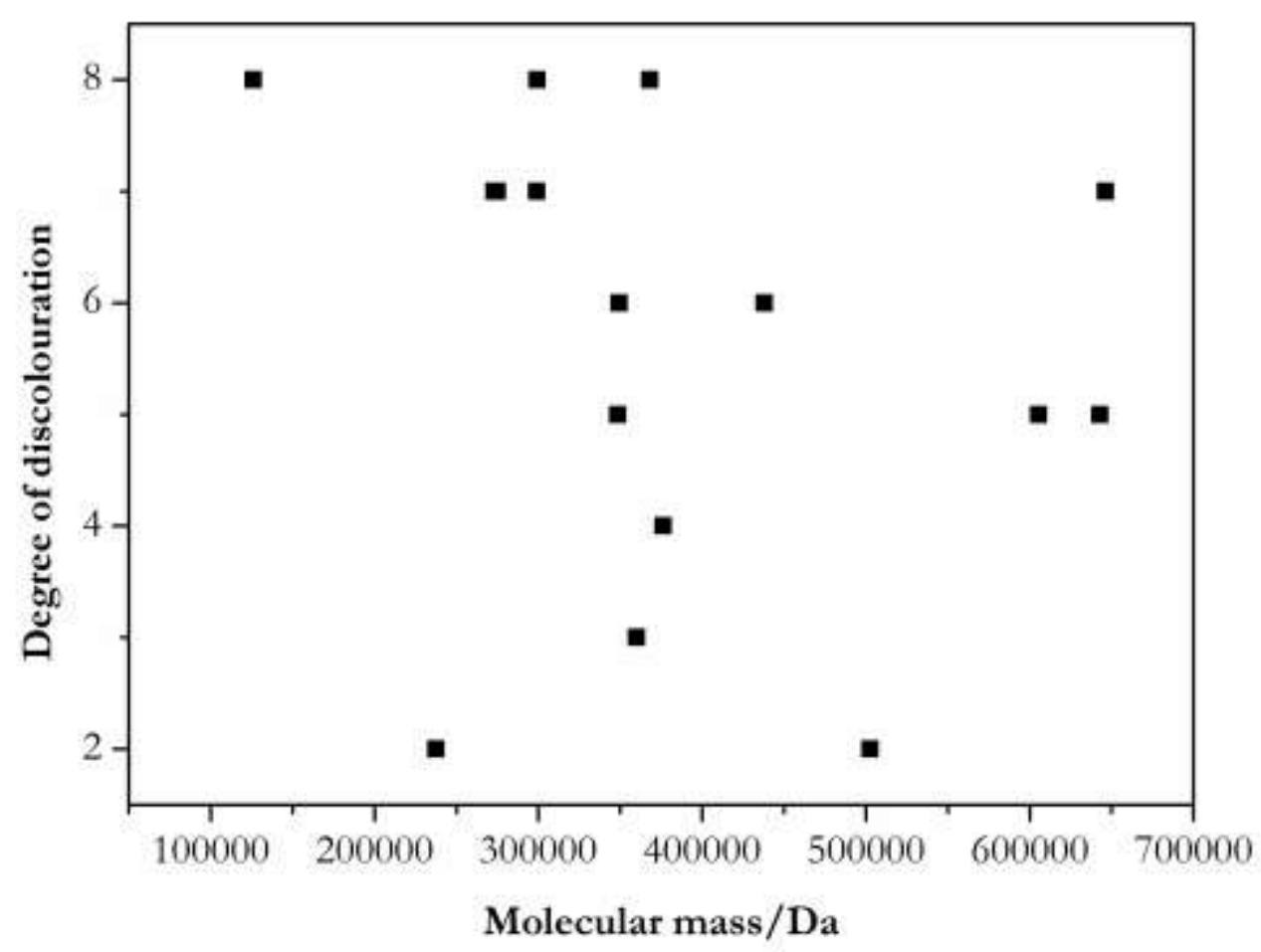

Fig. 1. Degree of discolouration of APS initiated PTFE samples as a function of the molecular mass according to Suwa's method.

Hence, it seems the discolouration of PTFE initiated by APS, SPS or other such initiators cannot be ascribed solely to the type and concentrations of end-groups heretofore reported and more 
information is needed about the microstructure of PTFE synthesised with the initiators for which discolouration is observed.

\subsection{FTIR and Raman spectroscopy}

FTIR and Raman spectra were obtained for each sample, before and after sintering. The FTIR and Raman spectra for commercial PTFE initiated with a perfluoro-initiator is presented in Fig. 2 and Fig. 4, respectively. Fig. 3 shows an enlarged section of Fig. 2. A FTIR spectrum for PTFE initiated with APS is presented in Fig. 5 and a Raman spectrum for PTFE initiated by $\mathrm{KMnO}_{4}$ is presented in Fig. 7. Fig. 6 shows an enlarged area of Fig. 5. The FTIR and Raman spectra for all the other PTFE samples are included in the supporting information.

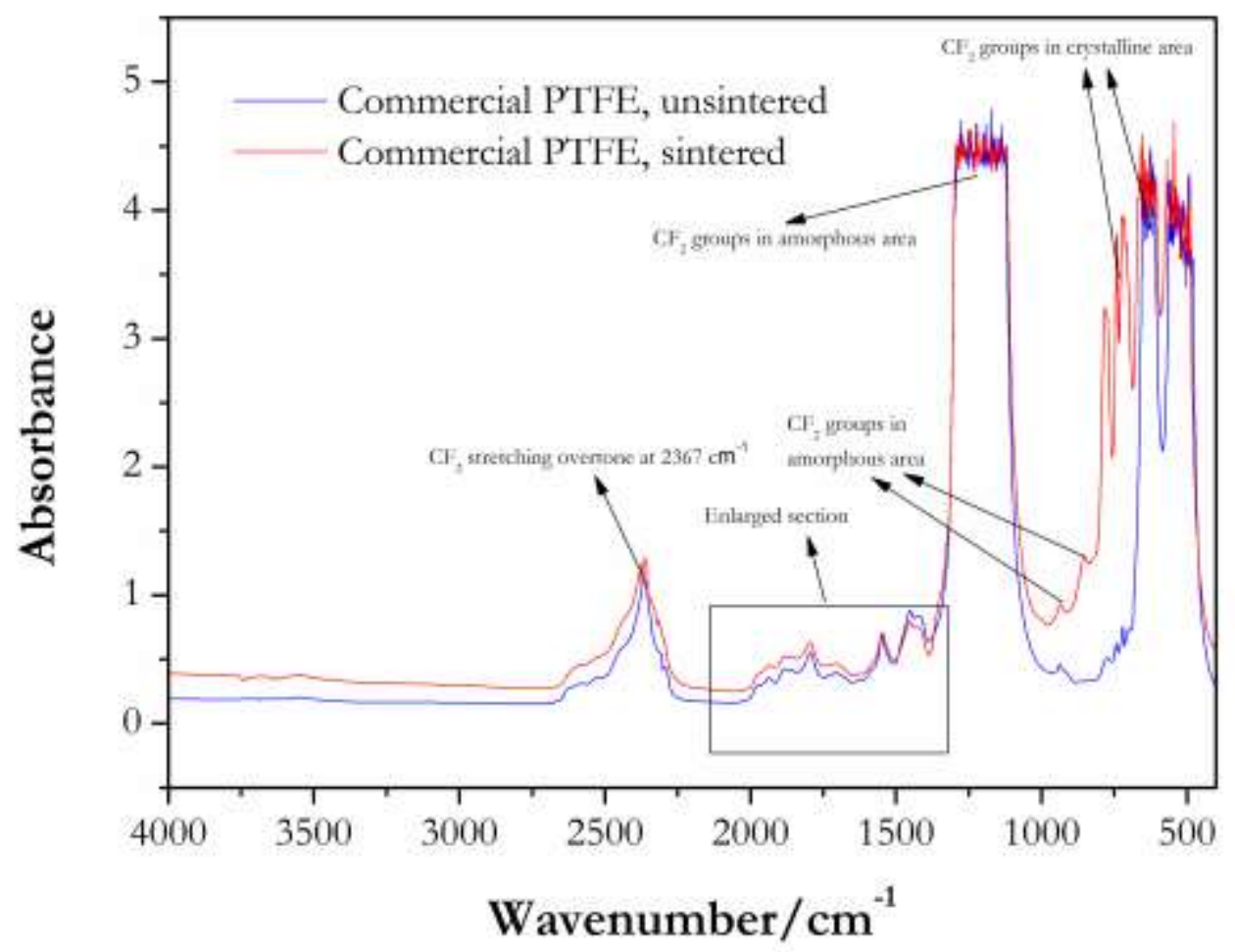

Fig. 2. FTIR spectra of commercial PTFE, before and after sintering. The only change after sintering was the increase of the crystalline signals at $700 \mathrm{~cm}^{-1}$. The enlarged section can be seen in Fig. 3. 


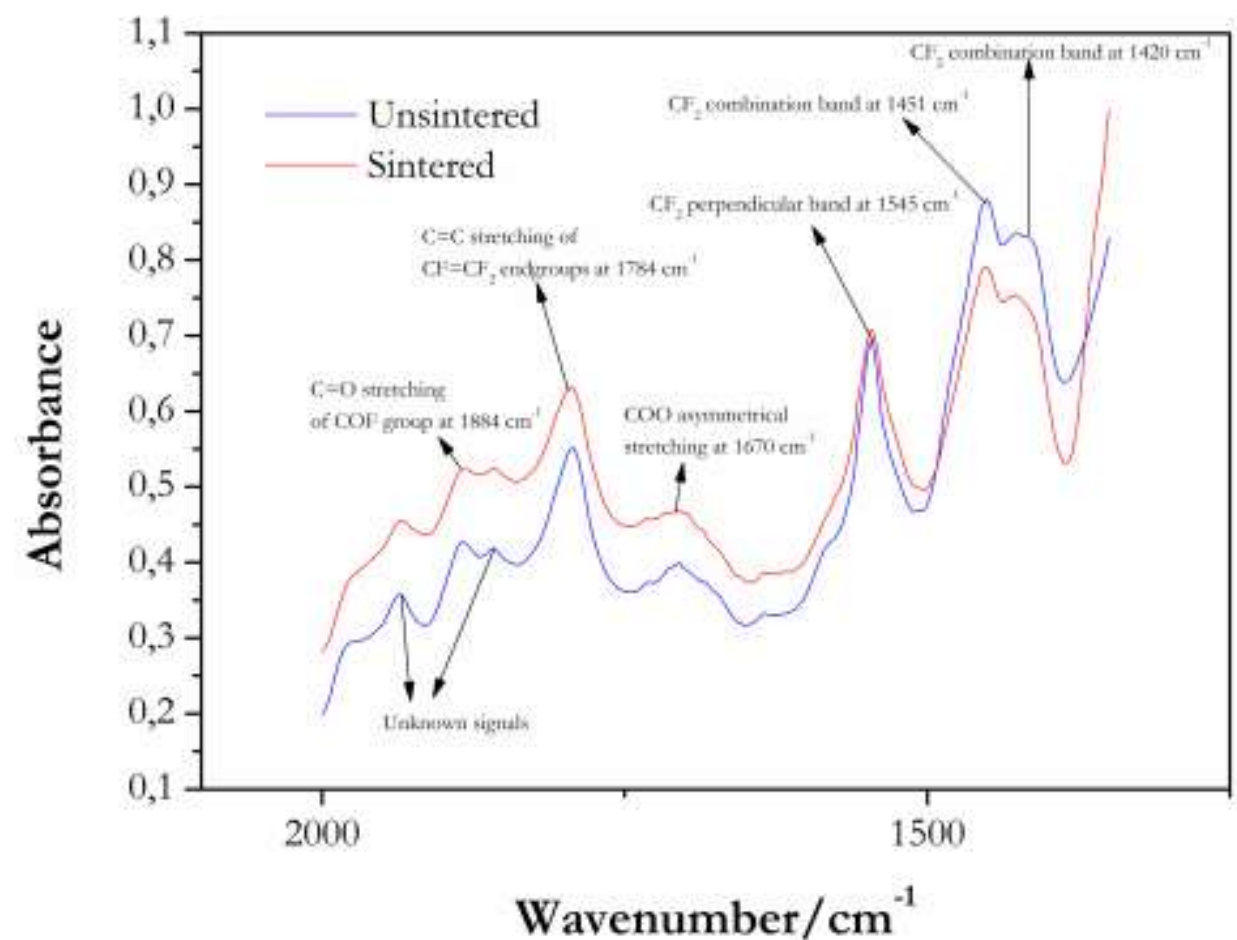

Fig. 3. Enlarged section of Fig. 2. No changes occurred after sintering.

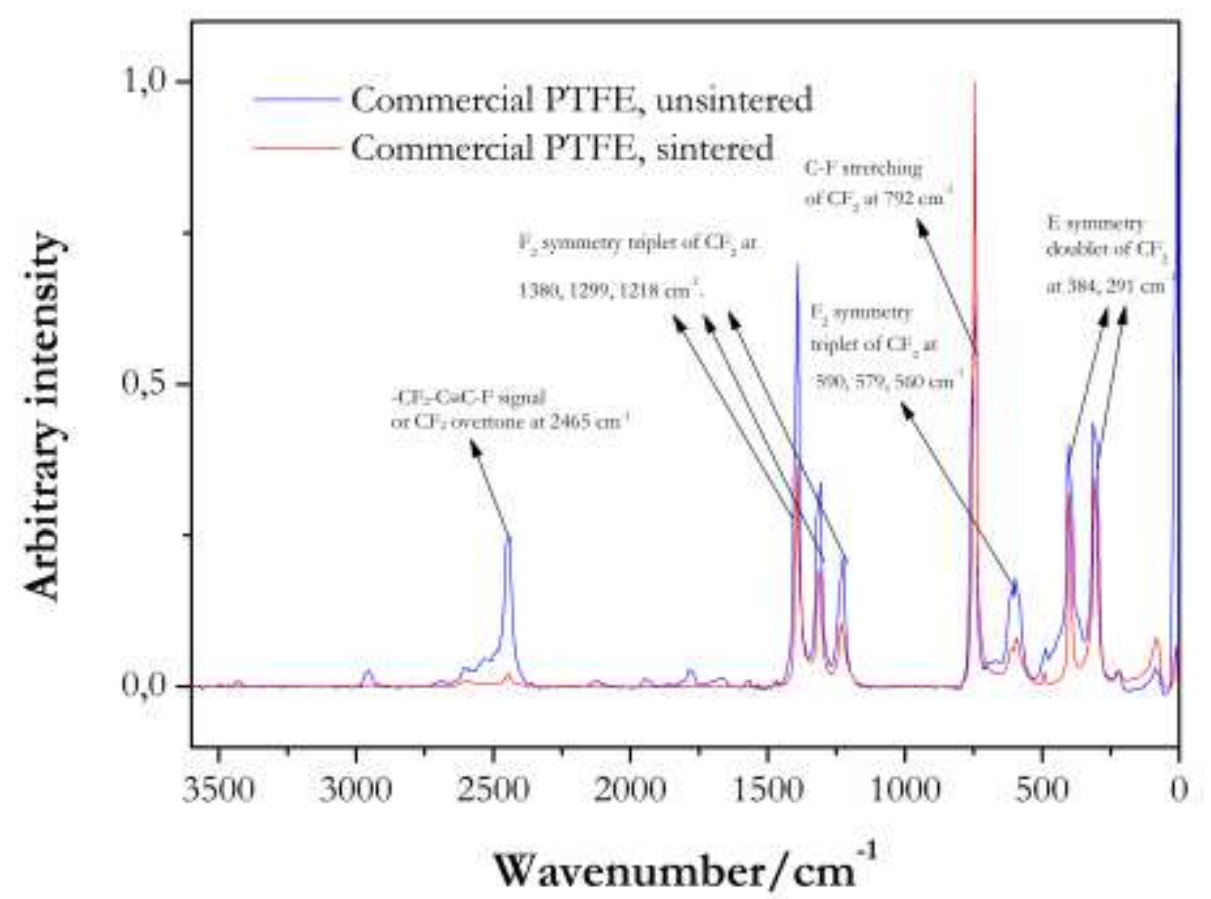

Fig. 4. Raman spectra of commercial PTFE, pre- and post-sintering. All the signals indicate the structure of PTFE. The unknown signal at $2450 \mathrm{~cm}^{-1}$ decreases significantly after sintering. It is believed this indicates a conformational change in the PTFE structure. 


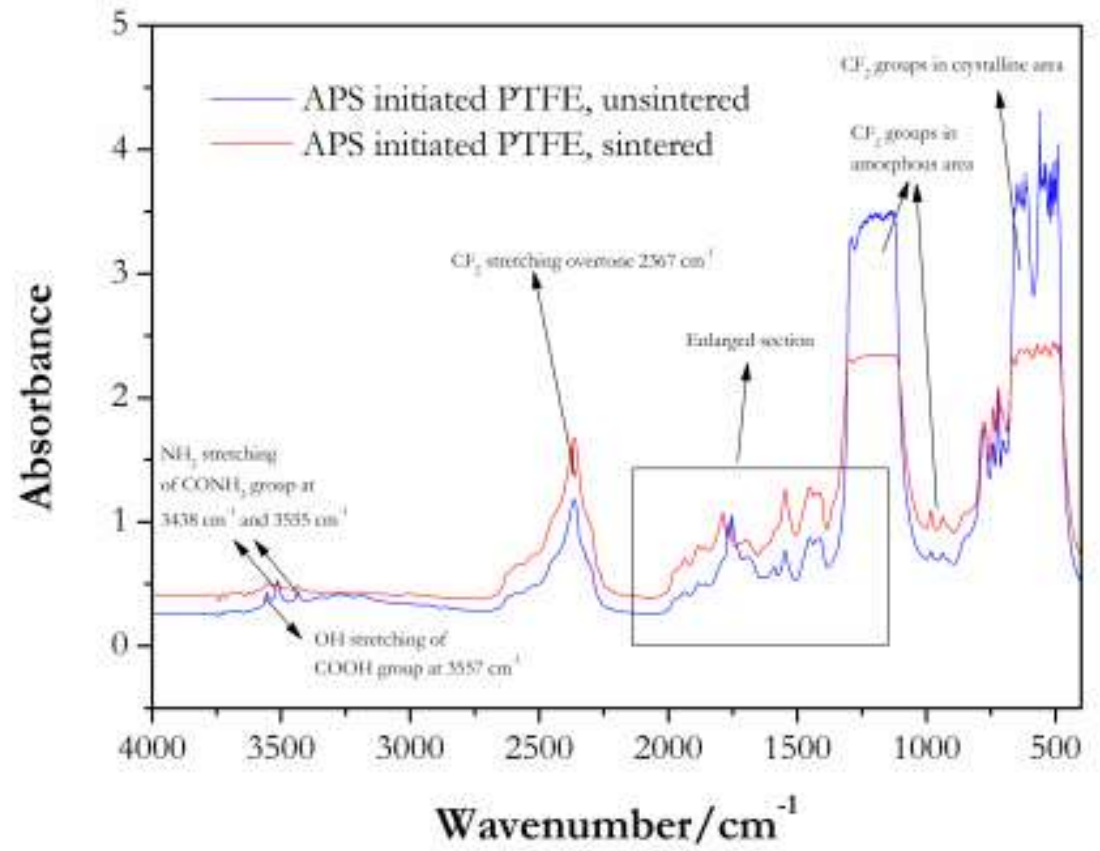

Fig. 5. FTIR spectra of a low $M_{n}$, APS initiated PTFE, before and after sintering. Significant changes occur in the enlarged section and in the region of $\sim 3555 \mathrm{~cm}^{-1}$, where the $\mathrm{NH}_{2}$ and $\mathrm{COOH}$ signals decrease. The enlarged section can be seen in Fig. 6.

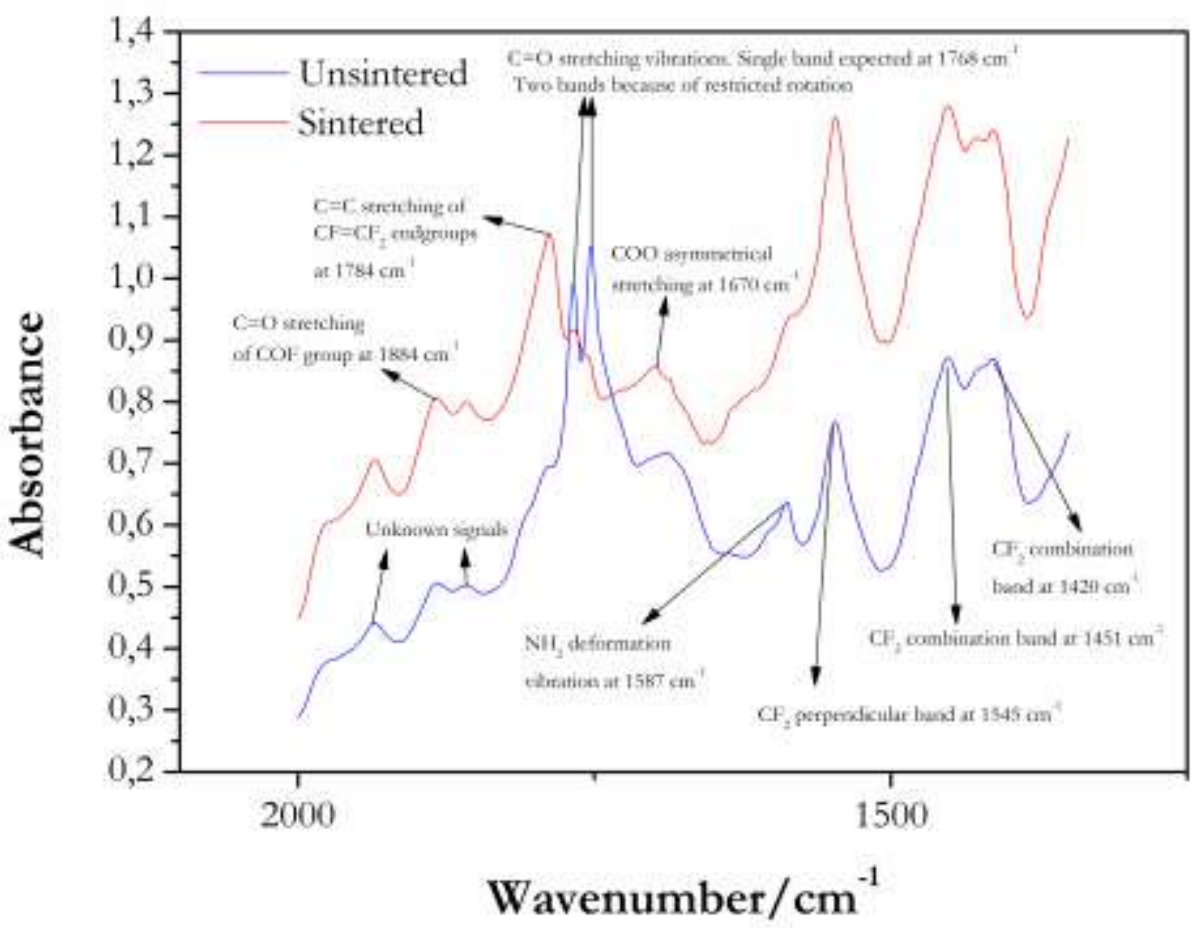

Fig. 6. Enlarged area from Fig. 5. It is clear that the $\mathrm{NH}_{2}$ signal decreases, as well as the $\mathrm{C}=\mathrm{O}$ stretching bands of the $\mathrm{COOH}$ group. A strong $\mathrm{CF}=\mathrm{CF}_{2}$ signal appears. The $\mathrm{COF}$ signal stays approximately the same. 


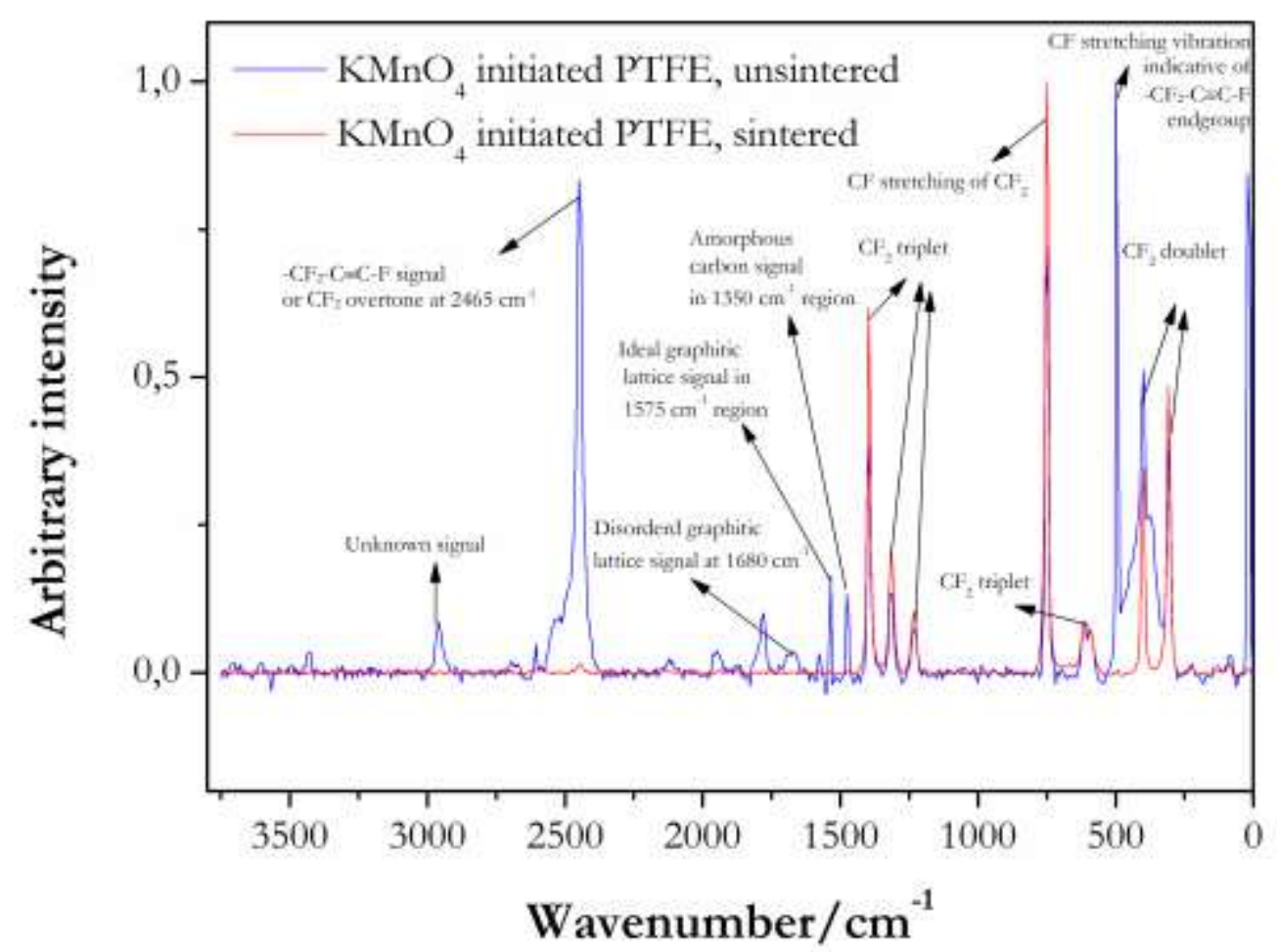

Fig. 7. Raman spectra of $\mathrm{KMnO}_{4}$ initiated PTFE, before and after sintering. The same signals that were indicative of the structure of PTFE in the commercial sample appear here. Similarly to the commercial sample, the same strong signal appears at $\sim 2450 \mathrm{~cm}^{-1}$ and disappears after sintering. An additional strong signal appears at $\sim 450 \mathrm{~cm}^{-1}$ and is absent after sintering. It is not clear what this signal represents.

The IR and Raman absorption bands of the intrinsic chain vibrations of-, as well as the end-groups reported in PTFE were obtained from various literature sources [26, 31-40] and are summarised in Table 3, Table 4, respectively. Where possible, end-groups for the samples were identified by comparing the obtained spectra to literature references $[26,41,42]$. These assignments are provided in Table 5.

Information regarding the IR and Raman spectra of some of the expected terminal structures was difficult to find in the literature and in the few places where information was found, functional groups containing fluorine bonds were not always covered. Sources discussing bonds with the other halogens, namely I, $\mathrm{Br}$ and $\mathrm{Cl}$, were found in several instances [42, 43]. From these published wavenumbers, it was deduced that with increasing electron negativity, $\mathrm{I}<\mathrm{Br}<\mathrm{Cl}$, the wavenumber of the spectral bands seemed to shift approximately $50 \mathrm{~cm}^{-1}$ higher for each successively more 
electron negative halogen. By assuming this trend continued with fluorine, spectral bands were expected at $\sim 50 \mathrm{~cm}^{-1}$ higher than the equivalent active groups that contained chlorine.

Table 3: Assignments of IR signals for PTFE and possible end groups as reported by various authors

\begin{tabular}{|c|c|c|c|c|}
\hline $\begin{array}{l}\text { Wavenumber } \\
\left(\mathrm{cm}^{-1}\right)\end{array}$ & Group & & Assignment & Reference \\
\hline 3557 & $\mathrm{COOH}$ & & $\mathrm{OH}$ stretching & [26] \\
\hline 3555 & $\mathrm{CONH}_{2}$ & & $\mathrm{NH}_{2}$ asymmetric stretching & [26] \\
\hline 3438 & $\mathrm{CONH}_{2}$ & & $\mathrm{NH}_{2}$ symmetric stretching & [26] \\
\hline \multirow[t]{2}{*}{$3300-3000$} & $\mathrm{COOH}$ & (Hydrogen & OH stretching & [26] \\
\hline & bonded) & & & \\
\hline 3005 & $\mathrm{CF}_{2} \mathrm{H}$ & & $\mathrm{CH}$ stretching & [26] \\
\hline 3003 & $\mathrm{CH}_{2} \mathrm{CH}_{3}$ & & $\mathrm{CH}$ stretching & [26] \\
\hline 2465 & $\mathrm{C} \equiv \mathrm{C}-\mathrm{F}$ & & $\mathrm{C} \equiv \mathrm{C}$ skeletal vibration & $\mathrm{Ab}$ initio calculations \\
\hline 2367 & $\mathrm{CF}_{2}$ & & $\mathrm{CF}_{2}$ stretching overtone & [41] \\
\hline 2330 & $\mathrm{CF}_{2}$ & & $\mathrm{CF}_{2}$ stretching overtone & {$[42]$} \\
\hline 1884 & $\mathrm{COF}$ & & CO stretching & [26] \\
\hline 1813 & $\mathrm{COOH}$ & & CO stretching & [26] \\
\hline $1800-1780$ & $\mathrm{CF}=\mathrm{CF}_{2}$ & & $\begin{array}{l}=\mathrm{CF}_{2} \text { end-group due to } \\
\mathrm{C}=\mathrm{C} \text { stretching }\end{array}$ & [42] \\
\hline 1792 & $\mathrm{CF}_{2}$ & & $\mathrm{CF}_{2}$ combination band & [41] \\
\hline 1784 & $\mathrm{CF}=\mathrm{CF}_{2}$ & & CC stretching & [26] \\
\hline 1775 & $\begin{array}{l}\mathrm{COOH} \\
\text { bonded) }\end{array}$ & (Hydrogen & CO stretching & [26] \\
\hline 1768 & $\mathrm{CONH}_{2}$ & & CO stretching & [26] \\
\hline 1670 (broad) & $\mathrm{COO}^{-\mathrm{X}^{+}}$ & & $\begin{array}{l}\text { COO asymmetrical } \\
\text { stretching }\end{array}$ & [26] \\
\hline 1587 & $\mathrm{CONH}_{2}$ & & $\mathrm{NH}_{2}$ deformation motion & [26] \\
\hline 1545 & $\mathrm{CF}_{2}$ & & $\mathrm{CF}_{2}$ perpendicular band & [41] \\
\hline 1451 & $\mathrm{CF}_{2}$ & & $\mathrm{CF}_{2}$ combination band & [41] \\
\hline 1420 & $\mathrm{CF}_{2}$ & & $\mathrm{CF}_{2}$ combination band & [41] \\
\hline$\sim 1400,1300,1200$ & $\mathrm{C} \equiv \mathrm{C}-\mathrm{CF}_{3}$ & & $\begin{array}{l}\mathrm{C} \equiv \mathrm{C} \text { and } \mathrm{C}-\mathrm{F} \text { vibrational } \\
\text { bands }\end{array}$ & $\mathrm{Ab}$ initio calculations \\
\hline $1365-1325$ & $\mathrm{CF}_{2}-\mathrm{CF}_{3}$ & & $\begin{array}{l}\mathrm{CF}_{3} \text { end-group due to } \mathrm{C}-\mathrm{F} \\
\text { stretching }\end{array}$ & [42] \\
\hline
\end{tabular}




\begin{tabular}{|c|c|c|c|}
\hline $1340-1300$ & $\mathrm{CF}=\mathrm{CF}_{2}$ & $\begin{array}{l}=\mathrm{CF}_{2} \text { end-group due to } \mathrm{C}-\mathrm{F} \\
\text { stretching }\end{array}$ & [42] \\
\hline$\sim 1300$ & $\mathrm{C} \equiv \mathrm{N}$ & $\mathrm{C} \equiv \mathrm{N}$ vibrational band & $\mathrm{Ab}$ initio calculations \\
\hline $1245,1210,1155$ & $\mathrm{CF}_{2}$ & $\begin{array}{l}\mathrm{CF}_{2} \text { groups in amorphous } \\
\text { area }\end{array}$ & [44] \\
\hline 1180,1100 & $\mathrm{CF}_{3}$ & $\mathrm{CF}_{3}$ stretching vibrations & {$[45]$} \\
\hline $\begin{array}{l}935,835 \text { (very } \\
\text { narrow) }\end{array}$ & $\mathrm{CF}_{2}$ & $\begin{array}{l}\mathrm{CF}_{2} \text { groups in amorphous } \\
\text { area }\end{array}$ & [44] \\
\hline $778,738,718$ & $\mathrm{CF}_{2}$ & $\mathrm{CF}_{2}$ amorphous bands & [41] \\
\hline $745-730$ & $\mathrm{CF}_{2}-\mathrm{CF}_{3}$ & $\begin{array}{l}\mathrm{CF}_{3} \text { end-group due to } \mathrm{C}-\mathrm{F} \\
\text { stretching }\end{array}$ & [42] \\
\hline 700,520 & $\mathrm{CF}_{3}$ & $\mathrm{CF}_{3}$ deformation vibrations & {$[45]$} \\
\hline 638,625 & $\mathrm{CF}_{2}$ & $\begin{array}{l}\mathrm{CF}_{2} \text { groups in crystallised } \\
\text { area }\end{array}$ & [44] \\
\hline
\end{tabular}

Table 4: PTFE Raman assignments as reported by various authors

\begin{tabular}{|c|c|c|c|}
\hline $\begin{array}{l}\text { Wavenumber } \\
\left(\mathrm{cm}^{-1}\right)\end{array}$ & Group & Assignment & Reference \\
\hline 3774,3555 & $\mathrm{CONH}_{2}$ & $\mathrm{NH}_{2}$ stretching & $\mathrm{Ab}$ initio calculations \\
\hline 3744,750 & $\mathrm{COOH}$ & OH stretching & Ab initio calculations \\
\hline $3005-2975$ & $\mathrm{CHF}_{2}$ & Asymmetrical stretching & {$[42]$} \\
\hline $3000-2960$ & $\mathrm{CH}_{2} \mathrm{CH}_{3}$ & $\begin{array}{l}\text { Asymmetrical } \quad \mathrm{CH}_{3} \\
\text { stretching }\end{array}$ & {$[42]$} \\
\hline 2465 & $\mathrm{C} \equiv \mathrm{C}-\mathrm{F}$ & $\mathrm{C} \equiv \mathrm{C}$ skeletal vibrations & Ab initio calculations \\
\hline 2403 & $\mathrm{C} \equiv \mathrm{C}-\mathrm{CF}_{3}$ & $\mathrm{C} \equiv \mathrm{C}$ skeletal vibrations & $\mathrm{Ab}$ initio calculations \\
\hline 2388 & $\mathrm{C} \equiv \mathrm{N}$ & $\mathrm{C} \equiv \mathrm{N}$ skeletal vibrations & $\mathrm{Ab}$ initio calculations \\
\hline $1800-1780$ & $\mathrm{CF}=\mathrm{CF}_{2}$ & $\begin{array}{l}=\mathrm{CF}_{2} \text { end-group due to } \\
\mathrm{C}=\mathrm{C} \text { stretching }\end{array}$ & {$[42]$} \\
\hline $1790-1755$ & $\mathrm{COOH}$ & CO stretching vibration & [42] \\
\hline $\begin{array}{l}\text { 1380, 1299, } 1218 \\
\text { triplet }\end{array}$ & $\mathrm{CF}_{2}$ & $\begin{array}{l}\text { Splitting of } \mathrm{F}_{2} \text { symmetry } \\
\text { line }\end{array}$ & {$[44]$} \\
\hline $1365-1325$ & $\mathrm{CF}_{2}-\mathrm{CF}_{3}$ & $\begin{array}{l}\mathrm{CF}_{3} \text { end-group due to } \mathrm{C}-\mathrm{F} \\
\text { stretching }\end{array}$ & [42] \\
\hline $1340-1300$ & $\mathrm{CF}=\mathrm{CF}_{2}$ & $\begin{array}{l}=\mathrm{CF}_{2} \text { end-group due to } \mathrm{C}-\mathrm{F} \\
\text { stretching }\end{array}$ & {$[42]$} \\
\hline
\end{tabular}




\begin{tabular}{llll}
\hline 1281,628 & $\mathrm{CF}_{2}$ & $\mathrm{~F}_{2}$ symmetry & {$[44,46]$} \\
908 & $\mathrm{CF}_{2}$ & A $_{1}$ symmetry & {$[44,46]$} \\
792 & $\mathrm{CF}_{2}$ & C-F stretching & {$[44,46]$} \\
$745-730$ & $\mathrm{CF}_{2}-\mathrm{CF}_{3}$ & $\mathrm{CF}_{3}$ end-group due to C-F & {$[42]$} \\
& & stretching & \\
$590, \quad 579, \quad 560$ & $\mathrm{CF}_{2}$ & Splitting of $\mathrm{F}_{2}$ symmetry & {$[44]$} \\
triplet & & line & \\
435 & $\mathrm{CF}_{2}$ & E symmetry & {$[44,46]$} \\
384,291 & $\mathrm{CF}_{2}$ & Splitting of E symmetry & {$[44]$} \\
& & mode & \\
\hline
\end{tabular}

Table 5: $\quad$ Initiators used in PTFE syntheses and subsequent end-groups before sintering

\begin{tabular}{|c|c|c|c|c|c|c|c|c|c|}
\hline Initiator & Exp. \# & & & & & & & & \\
\hline End-groups & & $-\mathrm{COOH}$ & $-\mathrm{COO}^{+} \mathrm{X}^{-}$ & $-\mathrm{CONH}_{2}$ & $-\mathrm{C} \equiv \mathrm{C}-\mathrm{F}$ & $-\mathrm{COC}\left(\mathrm{CH}_{2}\right)_{2}$ & $\mathrm{OH}$ & $\mathrm{CFO}$ & $\mathrm{CF}=\mathrm{CF}_{2}$ \\
\hline Commercial & - & & $\checkmark$ & & $\checkmark$ & & & $\checkmark$ & $\checkmark$ \\
\hline APS (Borax) & $1,4-17$ & $\checkmark$ & $\checkmark$ & $\checkmark$ & $\checkmark$ & & & & \\
\hline APS & 2 & $\checkmark$ & $\checkmark$ & & $\checkmark$ & & & & \\
\hline $\mathrm{APS}\left(\mathrm{K}_{2} \mathrm{CO}_{3}\right)$ & 3 & $\checkmark$ & & & $\checkmark$ & & & & \\
\hline SPS & 18,19 & $\checkmark$ & & & $\checkmark$ & & & & \\
\hline $\mathrm{KMnO}_{4}$ & $20-22$ & & & & $\checkmark$ & & $\checkmark$ & & \\
\hline DTBP & $23-25$ & & & & $\checkmark$ & $\checkmark$ & & & \\
\hline
\end{tabular}

However, because there was some uncertainty regarding the accuracy of these estimated values, the IR and Raman spectra of the expected end-group structures were also predicted by ab initio methods using the SPARTAN software package [47]. In most cases the calculated spectral bands corresponded quite well with the bands estimated by the frequency shift assumption.

The IR and Raman spectra of commercial PTFE showed evidence of acyl fluoride (COF), $\mathrm{CF}=\mathrm{CF}_{2}$ and $\mathrm{COO}^{+} \mathrm{X}$ end-groups. After sintering it showed no changes in the structure of commercial PTFE, except for an increase in crystallinity as evidenced by an increase in intensity of the signals in the region of $700 \mathrm{~cm}^{-1}$.

The IR and Raman spectra for PTFE initiated with APS indicated that the synthesised samples possessed several different end-groups. The samples synthesised with borax as buffering agent contained carboxylate, ionic carboxylate and amidic end-groups. This suggests multiple termination reactions. APS initiated samples that used potassium carbonate as buffering agent had 
no ionic carboxylate end-groups and no amidic end-groups. The APS initiated sample that did not include a buffering agent in the reaction also had multiple termination reactions, with the IR and Raman spectra indicating the presence of carboxylic and carboxylic salt end-groups in lower concentrations, but no amide end-groups.

The APS initiated sample that used borax as buffering agent experienced significant discolouration during sintering. The FTIR results of the sintered samples showed that the carboxylic acid and amidic end-groups were at least partially eliminated during sintering. The disappearance of two bands at $\sim 1750 \mathrm{~cm}^{-1}$ and the appearance of a new signal at $\sim 1780 \mathrm{~cm}^{-1}$ indicated the elimination of carboxylic end-groups and the formation of $\mathrm{CF}=\mathrm{CF}_{2}$ end-groups. Similarly, the sample where potassium carbonate was used as buffering agent underwent significant discolouration and shows no evidence of the carboxylic acid or amidic end-groups after sintering, meaning these end-groups must have undergone an elimination reaction. The sample where no buffering agent was used discoloured upon sintering, though significantly less than the other two samples. The FTIR results suggest that some of the carboxylic acid end-groups of this sample decomposed into acyl fluoride groups. The end-group assignments for the sintered samples can be seen in Table 6 .

Table 6: $\quad$ Initiators used in PTFE syntheses and subsequent end-groups after sintering

\begin{tabular}{|c|c|c|c|c|c|c|c|c|}
\hline Initiator & Exp. \# & & & & & & & \\
\hline End-groups & & $-\mathrm{COOH}$ & $-\mathrm{COO}^{+} \mathrm{X}^{-}$ & $-\mathrm{CONH}_{2}$ & $-\mathrm{C} \equiv \mathrm{C}-\mathrm{F}$ & $-\mathrm{COC}\left(\mathrm{CH}_{2}\right)_{2}$ & $\mathrm{OH}$ & $-\mathrm{CFO}$ \\
\hline Commercial & - & & & & $\checkmark$ & & & \\
\hline APS & $1,4-17$ & $\checkmark$ & & & & & & $\checkmark$ \\
\hline SPS & 18,19 & $\checkmark$ & & & & & & $\checkmark$ \\
\hline $\mathrm{KMnO}_{4}$ & $20-22$ & & & & & & \multicolumn{2}{|c|}{$\checkmark$} \\
\hline DTBP & $23-25$ & & & & & & & \\
\hline
\end{tabular}

Unlike the APS initiated samples, the SPS initiated samples were a translucent white colour before sintering. After sintering, they did not experience any significant discolouration. The FTIR spectra also indicated multiple termination modes for SPS initiated PTFE. The spectra showed evidence for high concentrations of carboxylic acid end-groups, and smaller concentrations of carboxylic salt end-groups. These samples did not discolour upon sintering. The post-sinter spectroscopic results show elimination of carboxylic end-groups and the formation of acyl fluoride end-groups.

The PTFE samples initiated by low concentrations of $\mathrm{KMnO}_{4}(1 \%$ and $10 \%)$ were white and translucent before sintering and did not exhibit any discolouration during sintering. This was not the case for the high initiator concentration (30\%) sample, which blackened completely after 
sintering. The $\mathrm{KMnO}_{4}$ initiated samples had similar end-groups to the commercial sample, with the addition of $\mathrm{OH}$ end-groups. The spectroscopic results of the $\mathrm{KMnO}_{4}$ initiated samples showed elimination of the $\mathrm{OH}$ end-groups after sintering. It is unclear which end-groups formed after this elimination, because no new peaks were present in the spectroscopic results after sintering.

The spectroscopic results of the DTBP initiated samples indicated the presence of tertiary butyl end-groups and the absence of carboxylic acid and carboxylic salt end-groups. The DTBP initiated samples showed little to no discolouration during sintering, which indicated the tertiary butyl endgroups were stable and not easily eliminated at elevated temperatures.

The FTIR and Raman spectra indicate that there are no moieties which could correspond to a conjugated p-orbital system. It seems the terminal structures are the same for both uncoloured samples and samples which exhibited pronounced discolouration. This indicates that the endgroups themselves are not the cause, or at least, not the sole cause of the discolouration of PTFE.

There exists a possibility that the elimination reactions which occur during sintering produce chromophoric compounds that are not part of the PTFE chains, but are trapped in the PTFE matrix and thus give rise to the discolouration.

\subsection{TGA results}

The TGA-curves for commercial PTFE, APS, SPS, and DTBP are presented in the supporting information. The TGA curves for $\mathrm{KMnO}_{4}$ initiated PTFE are shown in Fig. 8.

The commercial PTFE sample did not exhibit any mass loss up to the bulk decomposition temperature. Importantly, the TGA-curves for commercial PTFE did not exhibit any evidence for post-pyrolysis residues. The APS initiated samples did not show any residual masses until an initiator ratio of $30 \%$. Similarly, for SPS initiated PTFE, some post-pyrolysis residual mass remained in the crucible up to approximately $800^{\circ} \mathrm{C}$. At an initiator ratio of $30 \%$, the $\mathrm{KMnO}_{4}$ initiated samples exhibited a residual mass of over 20\%. This residual masses remained approximately constant up to $1000^{\circ} \mathrm{C}$. When the gas was switched to oxygen, the residual mass rapidly disappeared.

A TGA experiment was conducted for PTFE initiated with $30 \% \mathrm{KMnO}_{4}$ in which the run was stopped at approximately $800{ }^{\circ} \mathrm{C}$. Visual inspection of the crucible revealed a black, glassy substance. This observation, along with the previously discussed disappearance of the mass under oxygen at $1000{ }^{\circ} \mathrm{C}$ suggested that the substance was carbon. Due to the fact that no evidence of graphitic or diamond-like signals in the Raman spectra was found, it is assumed that it was 
amorphous carbon that formed. There exists a possibility that the residue may be manganous, but none of the oxides of manganese which are stable up to $1000{ }^{\circ} \mathrm{C}$ will evaporate upon exposure to oxygen at that temperature [48].

There exists some correlation between the ratio of initiator and the post-pyrolysis residual mass, evidence for this can be seen in Fig. 9. There exists also some correlation between the degree of discoloration and the post-pyrolysis residual mass. This can be seen in Fig. 10.

These results seem to indicate that the discolouration of PTFE during sintering is due to the deposition of non-volatile elimination products within the polymer matrix. The mass of residue is insufficient for further analysis by XPS or SEM-EDX, but the thermogravimetric behaviour seems to indicate that this residue is amorphous carbon. No mechanism can yet be proposed to explain how elemental carbon can form from the end-groups observed in PTFE that may undergo elimination.

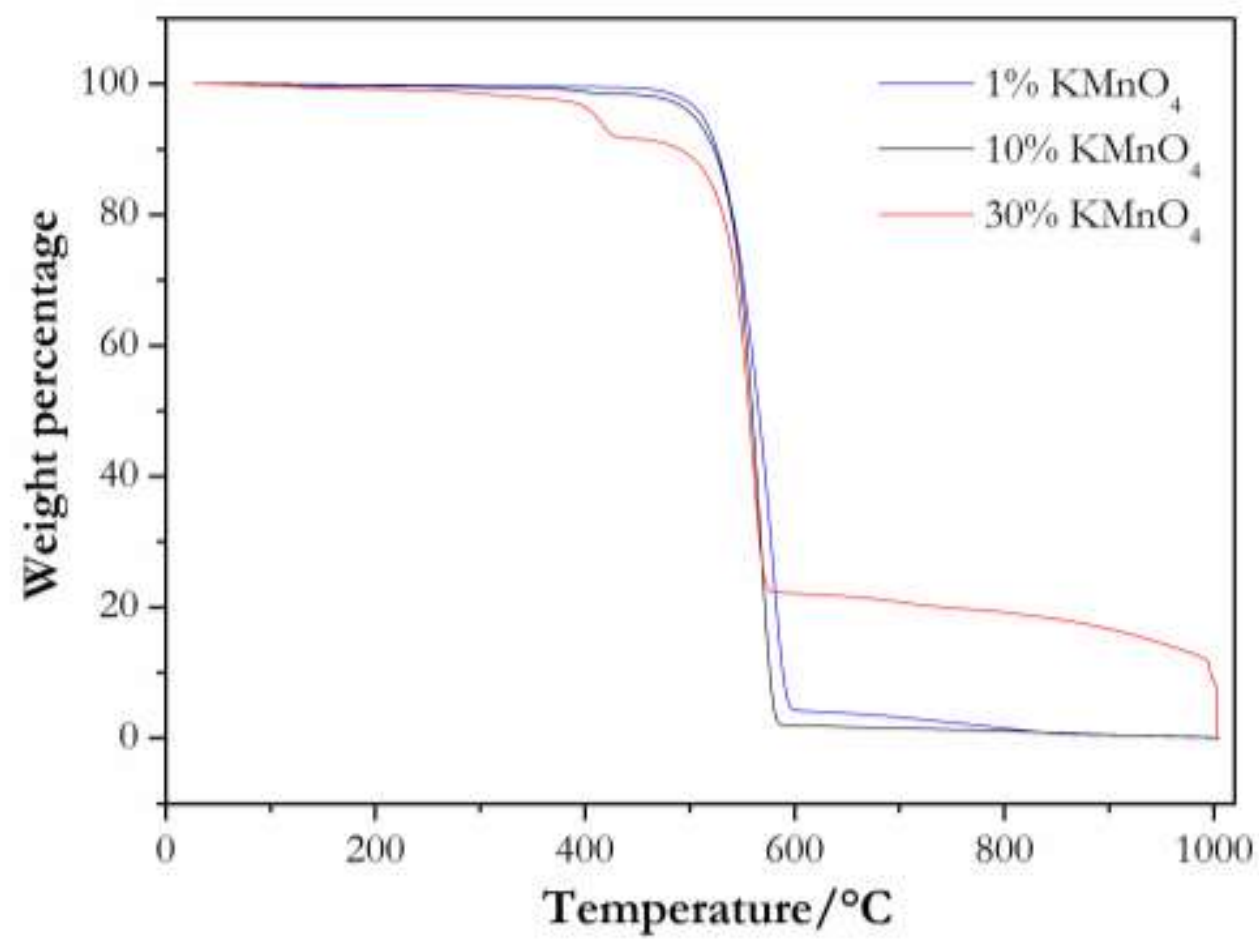

Fig. 8. TGA curves for $\mathrm{KMnO}_{4}$ initiated PTFE using different initiator concentrations. 


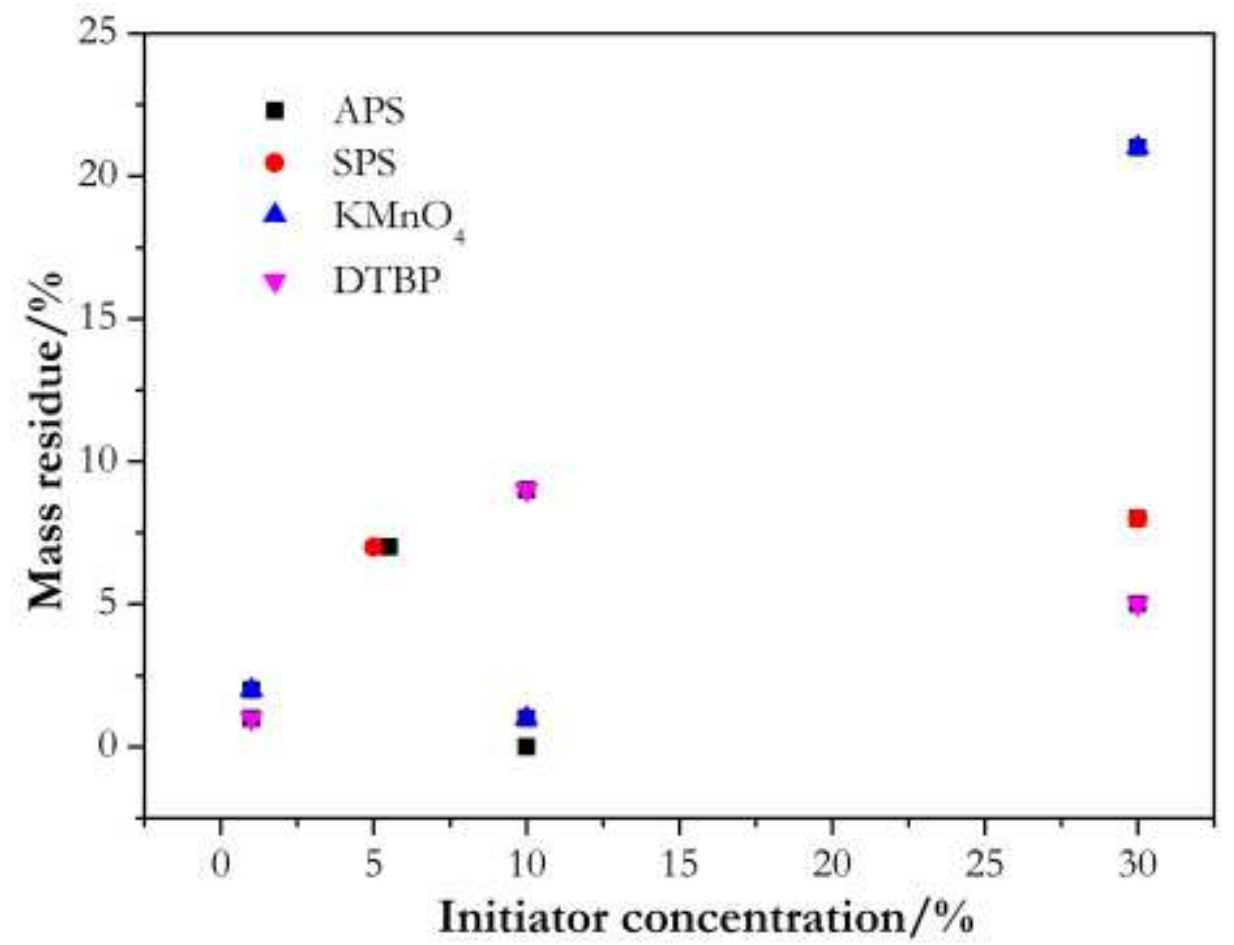

Fig. 9. Mass residue of samples after TGA analysis as a function of initiator concentration

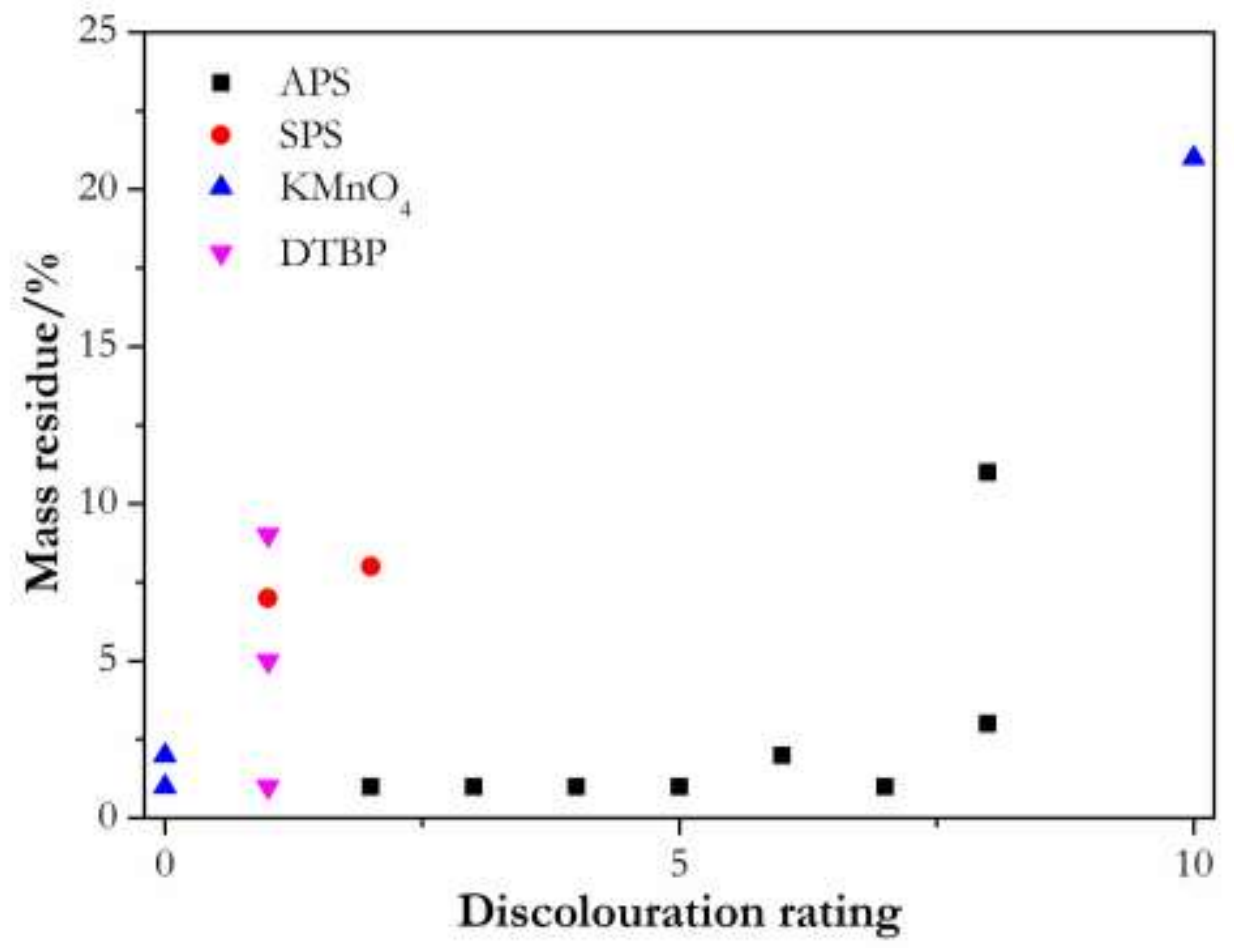

Fig. 10. Discolouration of samples as a function of the mass residue left over after TGA analysis 


\section{Conclusions}

The synthesised samples all had multiple termination reactions which lead to multiple end-groups forming which included: carboxylic end-groups, amide end-groups, carboxylic salt end-groups with $\mathrm{NH}_{4}{ }^{+}$and alkyne containing end-groups. The use of different buffering agents influenced the type and concentration of end-groups that formed, subsequently influencing discolouration at sintering temperatures and indicating that the phenomenon was not solely dependent on the initiator used.

The synthesised PTFE samples underwent physical changes at temperatures of approximately $380^{\circ} \mathrm{C}$. The pressed discs discoloured noticeably at these temperatures. Generally, with a few exceptions, the lower molecular weight samples were the ones which experienced the most discolouration. This lead to the conclusion that the lower molecular weight samples experience more discolouration, because of their higher concentration of end-groups.

The spectroscopic results showed that the carboxylic end-groups decomposed into acyl fluoride and perfluorovinyl groups during sintering. The alkyne, amidic, hydroxyl and carboxylic salt groups also decomposed, though it was not clear which new end-groups formed in their place. It is believed the discolouration was caused by amorphous carbon that was deposited into the polymer matrix after being eliminated from the end-groups. This was evidenced by the fact that low molecular weight samples showed residual weight up to $1000^{\circ} \mathrm{C}$. Once exposed to oxygen at this temperature, this mass quickly disappeared, indicating that this was in fact carbon. This was only evident with the high initiator concentration samples, as well as the samples that showed several termination modes and contained multiple end-groups.

Therefore, we conclude that the discolouration of PTFE during sintering is due to the elimination reactions from the chain ends producing carbonaceous deposits. This does not occur when initiators that produce stable end-groups, such as tertiary butyl groups or perfluorinated end-groups, are used.

\section{Experimental}

\subsection{Materials}

The PTFE used for producing TFE was Teflon ${ }^{\circledR}$ PTFE 807N X from DuPont. The initiators and buffering agents used were sourced commercially from Sigma-Aldrich. The water used was locally sourced de-mineralised and de-ionised water. 


\subsection{Methods}

\subsubsection{TFE depolymerisation}

TFE was produced by the vacuum pyrolysis PTFE as described by Smith et al. [49]. A stainless steel tube served as the depolymerisation vessel. PTFE granules were poured into this vessel, which was then inserted into a tube furnace where pyrolysis took place at $700{ }^{\circ} \mathrm{C}$. The depolymerisation vessel was coupled to a cold trap system, which condensed the gaseous TFE and by-products, once pyrolysis had taken place.

GC-MS analysis of the depolymerisation products indicated 93\% TFE, $6 \%$ hexafluoropropylene (HFP) and trace amounts of octafluorocyclobutane (OFCB) and perfluoroisobutylene (PFIB). This was deemed acceptable, because HFP does not readily polymerise and the other compounds were present in such small amounts so as not to adversely affect polymerisation.

\subsubsection{TFE polymerisation}

The TFE was polymerised in a $300 \mathrm{~mL}$ Parr Instruments autoclave using several initiators and water as solvent. For the first set of experiments, PTFE was synthesised using APS as initiator and sodium tetraborate decahydrate as the buffering agent, as per Brubaker's patent [50]. The initiator concentration and reaction temperatures of these experiments were varied to determine the effect on various aspects of the polymer product, including discolouration. The recipes for these polymerisation can be seen in Table 1. Another set of syntheses was performed using different initiators and initiator concentrations to determine the effect on discolouration of the polymer products. The recipes for these experiments can be seen in Table 2.

The autoclave was charged with an initiator, water and buffering agent and underwent three freeze-thaw cycles to remove atmospheric gases before gaseous TFE was added from the cold trap vessel. The frozen autoclave was then moved to the reactor cradle and connected to the reactor controller. Once the reactor had reached room temperature, the impeller and heater were activated. The impeller speed was set at a constant rate of $700 \mathrm{rpm}$. The temperature for each reaction was set according to the $1 \mathrm{~h}$ half-life of the initiator used. Each reaction was left to run overnight for 12 hours. The PTFEs formed were fine white powders suspended in water. The powders were then filtered and washed three times to ensure all impurities were removed. The filtered and washed powders were dried overnight at $80^{\circ} \mathrm{C}$. The samples were then ready for weighing and analysis. 


\subsubsection{Spectroscopic analysis}

The PTFE powders were pressed into thin discs using a custom made stainless steel die, with a diameter of $10 \mathrm{~mm}$, and a workbench press. Approximately $250 \mathrm{mg}$ of powder was weighed for each disc and pressed at 8 metric tons for a period of 2 minutes. The die produced discs with a diameter of $25 \mathrm{~mm}$. The thickness of the discs varied, but on average the thickness was approximately $300 \mu \mathrm{m}$.

The samples were analysed by spectroscopic methods to characterise the end-groups present. Transmission FTIR was chosen as the method of choice, because it gave a better representation of the overall sample than ATR spectroscopy, which only penetrates a few microns into the sample. Several sources $[41,42,51]$ report pressing powders at room temperature to give transparent films for the study of highly crystalline samples. Moynihan [41] also reports studying strong absorption in the $1200 \mathrm{~cm}^{-1}$ and $650-400 \mathrm{~cm}^{-1}$ regions by suspending powdered polymer in $\mathrm{KBr}$. When it was attempted to replicate these methods, several problems were encountered.

Firstly, when pressing the in-house produced PTFE powders at room temperature, the resulting films were opaque and very brittle, making FTIR measurements very difficult, if not impossible. Most, but not all, of the pressed discs of the APS initiated experiments were yellow in colour. This is a stark contrast to the pure white colour and high ductility of pressed discs of the commercial PTFE sample. It is believed that the yellow colour and brittleness of the produced PTFE samples was caused by different end-groups than the commercial PTFE samples, as well as lower $M_{n}$, resulting in the end-groups having a greater effect on the properties of the produced polymer.

When these powders were suspended in $\mathrm{KBr}$ and then pressed, the resulting spectra did not give a clear indication of the end-groups because the spectral region where the signals of end-groups were expected to be found was obscured. It is believed this interference was caused by water adsorbed onto the KBr. Drying the KBr overnight in an oven alleviated the problem slightly, but did not eliminate it altogether. To render the process facile and more repeatable, the PTFE powders were eventually pressed at an elevated temperature of approximately $180^{\circ} \mathrm{C}$, without the addition of any secondary materials. This temperature is well below the melting point of PTFE and did not cause any additional discolouration of the discs. This process resulted in transparent discs that were ductile enough to undergo FTIR spectroscopy.

\subsubsection{Sintering}

Sintering was carried out in a furnace. The furnace was allowed to reach a constant temperature of $380{ }^{\circ} \mathrm{C}$ after which the pressed PTFE discs were placed into the furnace inside an $\alpha$-alumina 
crucible. The discs were sintered for $30 \mathrm{~min}$. Some of the lower-molecular weight discs melted when subjected to $380{ }^{\circ} \mathrm{C}$. Once melted, the discs were impossible to extract from the crucible without destroying them, rendering them useless for transmission FTIR spectroscopy. This was because the discs had to have a minimum diameter of approximately $10 \mathrm{~mm}$ to cover the aperture in the instrument's sample holder. Powders of the samples that melted at $380{ }^{\circ} \mathrm{C}$ were again pressed into discs and subjected to a lower temperature of $360^{\circ} \mathrm{C}$. Temperatures lower than this fall outside the temperature ranges at which sintering normally takes place and were therefore avoided. Most of the discs were usable after this treatment and still showed discolouration. The pressed discs, unsintered and sintered, were analysed using FTIR and Raman spectroscopy.

\subsubsection{Thermal analysis}

TGA and DSC analyses were carried out on each sample.. Each sample was subjected to three heating/cooling cycles to erase any thermal history. The heat of crystallisation was determined by integrating the crystallisation peak on the third cycle. The heat of crystallisation was then used to determine the number average molecular mass of the polymer, according to the correlations of Suwa et al. [52] and Wiegel et al. as recommended by Lappan et al. [53]

\subsection{Instruments}

FTIR spectroscopy was carried out using a Perkin Elmer Spectrum 100 FTIR spectrometer using the transmission module. The samples were scanned from 4000 to $450 \mathrm{~cm}^{-1}$ at a resolution of $2 \mathrm{~cm}^{-1}$, with 32 accumulations being done for each sample.

Raman analysis was performed using a WITec Alpha 300R confocal Raman spectrometer instrument. The laser operated at an excitation wavelength of $532 \mathrm{~nm}$ and power of $6 \mathrm{~W}$. The samples were scanned using various combinations of different scan times and accumulations, the most common configuration being 20 accumulations of $20 \mathrm{~s}$ each.

Thermogravimentric analysis was performed using a Hitachi STA7300 TGA-DTA instrument. Approximately $10 \mathrm{mg}$ of sample was used for each run. Each sample was heated from $30{ }^{\circ} \mathrm{C}$ to $1000{ }^{\circ} \mathrm{C}$ at $10{ }^{\circ} \mathrm{C} \cdot \mathrm{min}^{-1}$ under and nitrogen atmosphere flowing at $200 \mathrm{~mL} \cdot \mathrm{min}^{-1}$.

Differential scanning calorimetry was performed on a Perkin Elmer DSC4000 with 12 mg dried polymer samples. The samples were heated from $20{ }^{\circ} \mathrm{C}$ to $430{ }^{\circ} \mathrm{C}$ at $10{ }^{\circ} \mathrm{C} \cdot \mathrm{min}^{-1}$ before being cooled to $20{ }^{\circ} \mathrm{C}$ at a rate of $10{ }^{\circ} \mathrm{C} \cdot \mathrm{min}^{-1}$, all under a nitrogen atmosphere flowing at a rate of 20 $\mathrm{mL} \cdot \mathrm{min}^{-1}$. 


\section{References}

[1] J.G. Drobny, Technology of Fluoropolymers, CRC Press, Boca Raton, Florida, 2014.

[2] D. O'Hagan, Understanding organofluorine chemistry. An introduction to the C-F bond, Chemical Society Reviews 37(2) (2008) 308-319.

[3] B. Ameduri, From vinylidene fluoride (VDF) to the applications of VDF-containing polymers and copolymers: Recent developments and future trends, Chemical Reviews 109(12) (2009) 66326686.

[4] J. Gardiner, Fluoropolymers: Origin, production, and industrial and commercial applications, Australian Journal of Chemistry 68(1) (2015) 13-22.

[5] S. Ebnesajjad, Fluoroplastics, Volume 1: Non-melt Processible Fluoroplastics, Elsevier Science, Norwich, New York, 2000.

[6] S. Ebnesajjad, Fluoroplastics, Volume 2: Melt Processible Fluoroplastics: The Definitive User's Guide, Elsevier Science, Norwich, New York, 2002.

[7] S. Ebnesajjad, Expanded PTFE Applications Handbook: Technology, Manufacturing and Applications, Elsevier Science, Norwich, New York, 2016.

[8] F. Boschet, B. Ameduri, (Co)polymers of chlorotrifluoroethylene: synthesis, properties, and applications, Chemical Reviews 114(2) (2013) 927-980.

[9] S.V. Gangal, P.D. Brothers, Perfluorinated polymers, polytetrafluoroethylene, Encyclopedia of Polymer Science and Technology, John Wiley \& Sons, Inc., New York, 2002.

[10] D.A. Hercules, C.A. Parrish, J.S. Thrasher, Research and Non-major Commercial Co- and Terpolymers of Tetrafluoroethylene, in: B. Ameduri, H. Sawada (Eds.), Fluorinated Polymers: Volume 2: Applications, The Royal Society of Chemistry, Croydon, United Kingdom, 2017, pp. 206-264.

[11] T.A. Tervoort, J.F. Visjager, B. Graf, P. Smith, Melt-Processable Poly(tetrafluoroethylene), Macromolecules 33 (2000) 6460-6465.

[12] T.A. Tervoort, J.F. Visjager, P. Smith, Melt-processable poly(tetrafluoroethylene)— compounding, fillers and dyes, Journal of Fluorine Chemistry 114(2) (2002) 133-137.

[13] R.J. Plunkett, Tetrafluoroethylene polymers, in: U.P. Office (Ed.) Kinetic Chemicals, Inc., 1941.

[14] T. Hyatt, Chemical Economics Handbook: Fluoropolymers, IHS Markit, London, United Kingdom, 2016.

[15] L. Wood, Global Fluoropolymers Products, Technologies and Applications Market Report 2016 - Research and Markets, Research and Markets, Dublin, Republic of Ireland, 2016, p. 588.

[16] V. Bhanu, K. Kishore, Role of oxygen in polymerization reactions, Chemical Reviews 91(2) (1991) 99-117.

[17] S. Ebnesajjad, Fluoroplastics, Volume 1 - Non-Melt Processible Fluoroplastics, William Andrew Publishing/Plastics Design Library2001.

[18] K.A. Edgar, N.D. Albert, Polymerization of tetrafluoroethylene with tertiary butyl peroxide or peracetate, E I du Pont de Nemours and Co, US, 1956.

[19] B. Felix, K. Hintzer, G. Lohr, Preparation of a modified polytetrafluoroethylene and use thereof, Hoechst AG, US, 1996.

[20] B. Felix, G. Lohr, W. Hofmeister, R. Hengel, Process for the preparation of tetrafluoroethylene polymer in aqueous suspension, Hoechst AG, US, 1992.

[21] R.L. Myers, Method for polymerizing tetrafluoroethylene, General Electric Co US, 1952.

[22] L.E. Scoggins, J.E. Mahan, Polymerization of tetrafluoroethylene, ConocoPhillips Co, US, 1971.

[23] C.R. Patrick, Thermal Stability of Polytetrafluoroethylene, Nature 181(4610) (1958) 698-698.

[24] D.A. Hercules, D.D. DesMarteau, R.E. Fernandez, J.L. Clark, J.S. Thrasher, Evolution of academic barricades for the use of tetrafluoroethylene (TFE) in the preparation of fluoropolymers, 
in: D.W. Smith, S.T. Iacono, S.S. Iyer (Eds.), Handbook of Fluoropolymer Science and Technology, John Wiley \& Sons, Inc., Hoboken, New Jersey, 2014, pp. 413-431.

[25] L. Madorskaya, N. Loginova, Y. Panshin, A. Lobanov, Role of end groups in polyvinylidene fluoride, Polymer Science USSR 25(10) (1983) 2490-2496.

[26] M. Pianca, E. Barchiesi, G. Esposto, S. Radice, End groups in fluoropolymers, Journal of Fluorine Chemistry 95(1-2) (1999) 71-84.

[27] K. Nassau, The fifteen causes of color: The physics and chemistry of color, Color Research \& Application 12(1) (1987) 4-26.

[28] R.J. Lewis, Hawley's Condensed Chemical Dictionary, Fifteenth ed., John Wiley \& Sons, Inc., Hoboken, New Jersey, 2007.

[29] A.V. Tobolsky, Dead-end Radical Polymerization, Journal of the American Chemical Society 80(22) (1958) 5927-5929.

[30] A.V. Tobolsky, C.E. Rogers, R.D. Brickman, Dead-end Radical Polymerization. II, Journal of the American Chemical Society 82(6) (1960) 1277-1280.

[31] M.I. Bro, C.A. Sperati, Endgroups in tetrafluoroethylene polymers, Journal of Polymer Science 38(134) (1959) 289-295.

[32] M.D. Buckmaster, Process for the stabilization of fluoropolymers, E I du Pont de Nemours and Co, US, 1992.

[33] P. Colaianna, J.A. Abusleme, N.D. Fanti, Process for preparing tetrafluoroethylene copolymers with other perfluorinated monomers, Solvay Specialty Polymers Italy SpA, European, 1997.

[34] D. Fischer, U. Lappan, I. Hopfe, K.-J. Eichhorn, K. Lunkwitz, FTi. r. spectroscopy on electron irradiated polytetrafluoroethylene, Polymer 39(3) (1998) 573-582.

[35] W.K. Fisher, J. Corelli, Effect of ionizing radiation on the chemical composition, crystalline content and structure, and flow properties of polytetrafluoroethylene, Journal of Polymer science: Polymer chemistry edition 19(10) (1981) 2465-2493.

[36] H.C. Gibbard, Stabilization of fluoropolymers, in: USPTO (Ed.) Asahi Glass Fluoropolymers USA Inc, US, 1993.

[37] J.F. Imbalzano, D.L. Kerbow, Stable tetrafluoroethylene copolymers, in: USPTO (Ed.) E I du Pont de Nemours and Co, US, 1988.

[38] R.A. Morgan, W.H. Sloan, Extrusion finishing of perfluorinated copolymers, in: USPTO (Ed.) E I du Pont de Nemours and Co, US, 1986.

[39] M.J. Pellerite, Unusual reaction chemistry in thermal decomposition of alkali metal 2-alkoxy2, 3, 3, 3-tetrafluoropropionate salts, Journal of Fluorine Chemistry 49(1) (1990) 43-66.

[40] H. Vanni, J. Rabolt, Fourier transform infrared investigation of the effects of irradiation on the 19 and $30^{\circ} \mathrm{C}$ phase transitions in polytetrafluoroethylene, Journal of Polymer Science: Polymer Physics Edition 18(3) (1980) 587-596.

[41] R.E. Moynihan, The Molecular Structure of Perfluorocarbon Polymers. Infrared Studies on Polytetrafluoroethylene1, Journal of the American Chemical Society 81(5) (1959) 1045-1050.

[42] G. Socrates, Infrared and Raman characteristic group frequencies: tables and charts, John Wiley \& Sons2004.

[43] A. Kuptsov, G.N. Zhizhin, Handbook of Fourier transform Raman and infrared spectra of polymers, Elsevier1998.

[44] G. Legeay, A. Coudreuse, J.-M. Legeais, L. Werner, A. Bulou, J.-Y. Buzaré, J. Emery, G. Silly, AF fluoropolymer for optical use: spectroscopic and surface energystudies; comparison with other fluoropolymers, European Polymer Journal 34(10) (1998) 1457-1465.

[45] M.A.A. Beg, H.C. Clark, CHEMISTRY OF THE TRIFLUOROMETHYL GROUP: PART V. INFRARED SPECTRA OF SOME PHOSPHORUS COMPOUNDS CONTAINING CF3, Canadian Journal of Chemistry 40(3) (1962) 393-398. 
[46] S. Firsov, G. Zhbankov, M. Bakhramov, A. Abdukadyrov, A. Gafurov, Raman spectra and structure of polytetrafluoroethylene subjected to elastic deformation grinding, Journal of Applied Spectroscopy 59(3) (1993) 644-647.

[47] I. Wavefunction, Spartan'06, Wavefunction, Inc., Irvine, CA.

[48] K. Terayama, M. Ikeda, Study on Thermal Decomposition of $\mathrm{MnO}_{2}$ and $\mathrm{Mn}_{2} \mathrm{O}_{3}$ by Thermal Analysis, Transactions of the Japan Institute of Metals 24(11) (1983) 754-758.

[49] D.W. Smith, S.T. Iacono, S.S. Iyer, Handbook of fluoropolymer science and technology, John Wiley \& Sons2014.

[50] M.M. Brubaker, Process for polymerizing tetrafluoroethylene, E I du Pont de Nemours and Co, US, 1946.

[51] U. Lappan, B. Fuchs, U. Geißler, U. Scheler, K. Lunkwitz, Number-average molecular weight of radiation-degraded poly(tetrafluoroethylene). An end group analysis based on solid-state NMR and IR spectroscopy, Polymer 43(16) (2002) 4325-4330.

[52] T. Suwa, M. Takehisa, S. Machi, Melting and crystallization behavior of poly(tetrafluoroethylene). New method for molecular weight measurement of poly(tetrafluoroethylene) using a differential scanning calorimeter, Journal of Applied Polymer Science 17(11) (1973) 3253-3257.

[53] U. Lappan, U. Geißler, L. Häußler, G. Pompe, U. Scheler, The estimation of the molecular weight of polytetrafluoroethylene based on the heat of crystallisation. A comment on Suwa's equation, Macromolecular Materials and Engineering 289(5) (2004) 420-425. 